\title{
A Components Oriented Method for Evaluation of E-government Information Systems Agility
}

\author{
Soumia Aggoune, Rabah Imache, Mohamed Mezghiche \\ LIMOSE Laboratory, Computer Science department \\ Faculty of Science, University of Boumerdes, Algeria
}

\author{
Abdelaziz Khadraoui \\ Institute of Services Science \\ university of Geneva-Switzerland
}

\begin{abstract}
Agility is simply defined as the ability of an entity (system, organization, human, etc.) to quickly accommodate unanticipated changes in order to face threats of its environment. The need for Agility within e-government is mainly due to the permanent changes in the environment (political, societal, economical, technological, etc.) which in turn cause changes in the governments' regulations and laws that may affect public organization's processes and systems. A change in one activity in a process or in one part of an e-government system may cause many problems in other parts of the same process or system. E-government information systems (e-GIS) in particular-present a higher degree of volatility in their environment, since requirement changes may stem from a number of sources including legislation changes, organizational reforms, end-user requirements, technological developments, interoperability and distribution concerns and so on. These changes impose from one hand, the need for continuous updating of e-GIS which are heterogeneous, distributed and fragmented to meet Front Office (citizens) and Back Office (internal organization) requirements. On the other hand the need for carrying these updates in agile manner ensuring overall consistency, since the success of egovernment projects depends strongly on the quality of their information systems. This paper deals with a practical method for the evaluation e-government information systems agility. This method is based on method engineering domain; and thus, it is built in the form of method components guiding the process of evaluation.
\end{abstract}

\section{Introduction}

Measuring and evaluating e-government information systems has become a priority for decision makers, as governments are increasingly asked to justify e-government investments, assess impacts and monitor e-government progress. Disseminating the results of monitoring and evaluation can be of great value to government decision makers, helping them building political reports of what being made, shaping the direction of e-government projects in support of better government agenda, return on investment mentality and culture of performance among government organizations. Exchange of experience in this area is thus of particular importance for those countries that are still in the early stages of e-government development so that they can avoid mistakes and learn from the other countries' success and failure experiences. However, it is difficult to talk about egovernment "success" or "failure" without a clear understanding of how to measure it. Sometimes countries set too high expectations as e-government objectives and fail to clearly define how to measure failure and success. This leads to an unbalanced measurement of success and failure. To respond to this problem, a range of measurement and evaluation tools (MAREVA, METER, CMT [1], etc.) have been developed and used by countries worldwide. Most of these tools realize static evaluations based on benchmarking the progress and assessing the status quo. However, the ever changing environment (political, legislative, social, economic, etc.) calls for a more dynamic evaluation aimed at encouraging mutual learning by exchanging knowledge from precedent experiences (benchlearning). This last necessitates -first of all- defining a clear objective of evaluation (readiness, availability, impact, etc.) in order to exchange the right knowledge about the right objective. Our work is in this scope and deals with agility as objective of evaluation.

It is now admitted through multiple projects and research tasks that are interested in e-government problems that evaluation of agility is one of the most neglected areas. However, this is not the result of omission; rather it reflects the degree of difficulty inherent in developing appropriate evaluative criteria and metrics. The difficulty is mostly due to the multidimensionality of the concept of agility, the multiple perspectives involved in evaluation, and sometimes the lack of knowledge about how to measure agility. The objective of this paper is to propose a practical method for evaluation of egovernment information systems (e-GIS) agility. The key idea behind this method is to combine the two fundamental parts of an e-GIS (FO and BO) with their operational parameters in order to evaluate its overall degree of agility. Moreover, a sample of evaluation parameters are defined to measure agility of each part, and a sample of evaluation criteria are defined to measure agility of each parameter. 
Evaluation metrics may be of different natures: (i) direct (ii) Adaptive (iii) Knowledge-based or (iv) Holistic [2]. So, in order to facilitate the interpretation of the results and unify the calculus, evaluation metrics are scored on a likert- 5 scale. One of the advantages of the proposed approach is that agility criteria are normalized to quantitative metrics, which allow decision makers to examine and compare different systems at different agility levels.

To construct our method "from scratch", we are based on methods engineering domain. A method according to this domain treats the two aspects of engineering: the process and the product, and thus comprises two elements: one or more product models and one or more process models [3]. The product is "the result to reach". The process is "the way which should be traversed to reach the result" [4]. Indeed, the product model prescribes what the awaited characteristics of the manufactured product are. The process model prescribes a manner of making, methodological steps to reach the target product. Within methods engineering, the decomposition of a method into components means the decomposition of its process model into method components. Each component presents appropriate guidelines that realize an intention/activity within the overall evaluation process.

The logical organization of this paper goes as follows. Section2 flies over the state of the art dealing with the concept of agility. Section $3-$ critically- analyzes the existing approaches dealing with approaches of evaluation of information systems agility. Section 4 presents our proposed approach. Finally, Section 5 clots this paper with conclusions and perspectives.

\section{Agility concept}

The concept of agility originated at the end of the eighties and the early nineties in the manufacturing area in the Unites States. Agile Manufacturing was first introduced with the publication of a report by IACCOCA Institute entitled " $21^{\text {st }}$ Century Manufacturing Enterprise Strategy" [5]. In this report agility was described as a new industrial order for competitiveness in a volatile manufacturing marketplace. Since then, the concept was extended to business processes and networks, supply chains, enterprise information systems, decision support systems, software development and so on.

Despite the age of the concept, there is no consensus yet on what agility exactly is. However, different facets of agility have been emphasized by multiple authors and this has led to varied views reflected in the literature. According to Kidd [6], agility is a broader concept that incorporates flexibility (which measures the ability of an enterprise to be aligned, with equivalent technology, to a given level of production); reactivity (which corresponds to the speed at which an enterprise responds to the changing demands of its customers, including unanticipated requests) and even adaptability (which is the ability to cope with newness which is often translates as positive and flexible attitude to meet needs for change within the enterprise). In developing their definition, Conboy and Fitz [7] defined agility as the continual readiness of an entity to rapidly or inherently, proactively or reactively embrace change, through high quality, simplistic, economical components and relationships with its environment. In turn, Goranson [8] interpreted agility as creativity and defined the enterprise agility as the ability to understand the environment and react creatively to both external and internal changes. Houghton [9] defined agility of information system (IS) as the ability to become vigilant. This suggests that agile IS should provide sufficient flexibility to respond to disruptions of "business as usual," either due to opportunities, threats, or unforeseen events. According to Desouza [10], being agile is generally result in the ability to sense signals in the environment, process them adequately, mobilize resources and processes to take advantage of future opportunistic, and continuously learn and improve the operations of enterprise. Finally, based on all these definitions, Stamos and Galanou [11] defined agility in terms of characteristics of the agile enterprise: (1) sensing, (2) learning, (3) adaptability, (4) resilience, (5) quickness, (6) innovation, (7) flexibility, (8) concurrency, and (9) efficiency.

\section{Agility evaluation approaches}

The works on evaluation of information systems agility can be mainly classified in evaluation of: enterprise information systems agility [12], manufacturing systems agility [2] and sociotechnical systems agility [13].

Within the context of enterprises, authors in [12] propose POIRE framework for the measurement of agility and durability of Enterprise Information Systems (EIS). POIRE refers to the five dimensions of an enterprise information system: Process, Organization, Information, Resources and Environment. In POIRE framework, agility is measured according to a certain number of agility factors which are defined for each dimension of the enterprise information system, using a set of evaluation criteria. These criteria are measured by some identified metrics, and the evaluation of the metrics is practically based on the evaluation of questions that are defined within the questionnaire of the corresponding dimension. Moreover, the authors propose a mechanism for regulation and preservation of agility. Regulation consists in equilibrating in time the levels of production and consummation of the EIS agility. Preservation consists in maintaining in 
time the EIS agility in a level, which will make it possible to maintain its durability (sustainability).

Within the manufacturing context, authors in [2] proposed a fuzzy logic-based framework to evaluate the agility of manufacturing information systems. In this framework, the authors proposed four infrastructures to evaluate the agility of manufacturing information systems: (1) production infrastructure, (2) market infrastructure, (3) people infrastructure, and (4) information infrastructure. These infrastructures are combined with their corresponding operational parameters to determine the overall value of the system agility. Then, the assessment of agility is based on an approximate reasoning method taking into account the knowledge that is included in fuzzy IF-THEN rules.

Finally, authors in [13] proposed a framework to evaluate the agility of information systems from the socio-technical perspective. In this last the information system is considered as composed of two sub-systems: a technical system and a social system. The technical sub-system encompasses both technology and process. The social sub-system encompasses the people who are directly involved in the IS and reporting the structure in which, these people are embedded. To measure the information system agility using the socio-technical perspective, the authors in [13] use the agility of the four components: (1) technology agility, (2) process agility, (3) people agility, and (4) structure agility. Hence, they argue that, the overall agility of the systems is not a simple summing of the obtained scores of agility in these four components, but it depends on their nonlinear relationships. To this end, they suggested the use of fuzzy logic membership functions for evaluating agility.

Although all these approaches are important -each one in the domain in which it is applied- their application for evaluation of e-government information systems agility will not work well. This is because e-government information systems differ from the author information systems in the fact that they encompass strategic political and social goals such as trust in government, social inclusion, community regeneration, community well-being, and sustainability rather than financial ones (costs, benefits, budgets, etc.) [14]. Accordingly, many authors criticize the use of such approaches to evaluating e-government information systems. According to Bannister [15], even when these approaches are applied rigorously, their relevance in the public service domain is questionable, because economic measures, such as value and financial returns, are very difficult to define in the public sector. In the same sense, Farby et al. [16] cited that the problems in these approaches include the limited definition of stakeholders, targeting only direct tangible costs and benefits, and they are based on accounting and financial instruments. However, for an evaluation effort to contribute to the information system success, appropriate approaches must be applied to the appropriate context. In response to this, many evaluation efforts in e-government information systems (E-GIS) were born. They tend to cover different aspects of the E-GIS that can be categorized in the two following groups:

- Approaches dealing with the Front-office aspect

- Supply approaches;

- Demand approaches;

- Approaches dealing with the Back office aspect.

The front-office aspect is studied from two complementary points of view: supply and demand [17]. Supply-side approaches entail evaluating online supply, and only in individual cases does it also involve supply via other channels of communication such as digital television, mobile technologies, call centers, dedicated kiosks and so on. These approaches generally investigate availability, level of development, quality and other characteristics of individual websites, and electronic portals as well as particular e-services and information content. On the other side, Demand-side approaches study the field from the users' (citizens and businesses) point of view. This kind of research primarily involves investigating actual use of websites, portals, eservices, information content, the level of interest in use and reasons for not using services as well as evaluations of the quality of services as perceived by the users and evaluation of their perceptions, requirements and needs. Finally, approaches dealing with evaluating the back-office aspect generally assess the internal adoption and use of information systems in organizations including data sharing and exchanging technologies (databases, document management, process and workflow management, data sharing and exchange, etc.).

A more detailed review of these approaches (Table.1) reveals that they are focused on a particular aspect of the e-government information system, whether it is front office (FO) or back office (BO). So far, there are few approaches that combine FO and BO aspects together. The majority of the approaches deal with the front-office aspect, evaluating the supply-side and less demand-side, while largely neglecting the back-office aspect. 
Table 1. Overview of E-GIS Evaluation Approaches [17]

\begin{tabular}{|c|c|c|c|}
\hline \multicolumn{4}{|c|}{ EGIS evaluation approaches } \\
\hline \multirow{2}{*}{ Studied by } & \multicolumn{2}{|c|}{$\begin{array}{c}\text { Front office } \\
\text { (FO) }\end{array}$} & \multirow{2}{*}{$\begin{array}{c}\text { Back } \\
\text { office } \\
\text { (BO) }\end{array}$} \\
\hline & $\begin{array}{l}\text { Demand } \\
\text { side }\end{array}$ & $\begin{array}{l}\text { Supply } \\
\text { side }\end{array}$ & \\
\hline Accenture & & $x$ & \\
\hline $\begin{array}{l}\text { Burgess and } \\
\text { Houghton }\end{array}$ & & $x$ & \\
\hline $\begin{array}{l}\text { Bartelsman } \\
\text { Foundation } \\
\text { BEGIX }\end{array}$ & & $x$ & \\
\hline $\begin{array}{l}\text { Canavate and } \\
\text { Navarro }\end{array}$ & & $x$ & \\
\hline $\begin{array}{l}\text { CapGemini \& } \\
\text { Young }\end{array}$ & & $x$ & \\
\hline Erin Research Inc. & $x$ & & \\
\hline Gant and Gant & & $x$ & \\
\hline Kaylor et al. & & $x$ & \\
\hline KEeLAN & & $x$ & \\
\hline Leben et al. & & $x$ & \\
\hline Momentum & $x$ & & \\
\hline NAO & & $x$ & \\
\hline NOIE and DMR & $x$ & $x$ & \\
\hline $\begin{array}{l}\text { Nordic Council of } \\
\text { Ministers }\end{array}$ & & $x$ & $x$ \\
\hline Vintar et al. & & & $x$ \\
\hline
\end{tabular}

This detailed review proves the opening supposition that current approaches do not support a comprehensive e-government assessment, but only partial evaluations that cannot give government decision makers the right elements for their decisions, especially not in the direction of transformative e-government, characterized by integrated services development, where quality highly depends on the integration of front office and back office systems together. It is against this backdrop that our contribution -presented in the next section- seeks to evaluate the agility of e-government information systems by combining the front office and back office together for a holistic evaluation of these e-GIS agility.

\section{The proposed approach}

\subsection{Conceptual Framework for Agility Evaluation}

As it had been said above, this framework conceptualizes the two fundamental parts of the eGIS: FO (Front Office) and BO (Back office). FO refers to the e-GIS external part and $\mathrm{BO}$ refers to the EGIS internal part. These parts (Figure 1) and the interactions between them, form a horizontal architecture that we argue generic and common for agility evaluation of all e-government information systems.

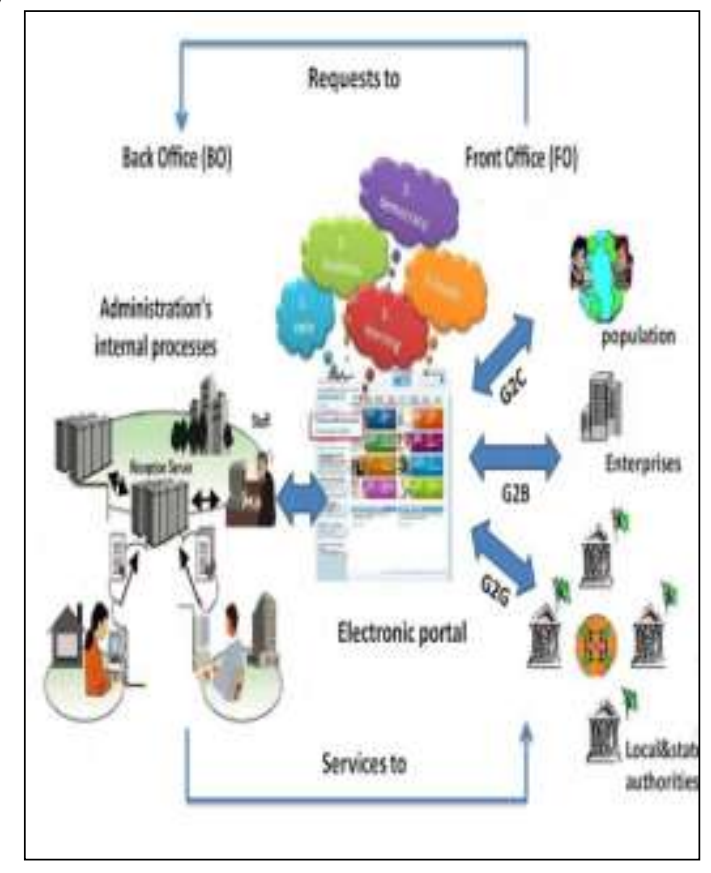

\section{Figure 1. E-government Information System main parts}

We define Front Office agility as the ability of an FO portal to satisfy in time its customers' requirements in spite of their access possibilities, skills, cultures, motivations, etc; and enhance communication and cooperation with the other governmental agencies. Indeed, the study of front office agility asks primarily to study interactions with citizens (G2C), businesses (G2B) and the interoperability with governmental agencies (G2G). The main parameters defined for the measurement of front office agility- are: reactivity, interoperability, availability, exhaustively, flexibility and security. Reactivity deals with the speed at which the FO portal responds to its customers' requirements and demands. Interoperability deals with the ability of the FO portal to communicate and cooperate with other existing or future on line portals. Availability refers to the continuity of providing services whatever changes or maintenance works. Exhaustively refers to the completeness and perenniality (non-missing information and services). Flexibility deals with the ability of providing personalized/customized services that include dynamically citizen's preferences, requirements, and needs. Finally, security concerns all the deployed safety measures/mechanisms that ensure confidentiality and integrity of the transferred information from end users to administration/institution and vice versa. 
We define back office agility as the ability of the organization's internal structure to adapt and reconfigure itself in time to support the different changes of the environment (legislative changes, citizens' requirements, technology evolution, etc) and to enhance the internal communication, collaboration and cooperation between the different internal departments (internal interoperability). The study of the back office agility concerns the study of its (i) organization agility (business processes and activities, business actors, business rules etc.), (ii) information agility (the circulated, processed and exchanged data and knowledge) and (iii) technology agility (the deployed platforms, architectures, implementation environments, etc.).

The parameters defined for the measurement of organization agility are: flexibility, effectiveness, efficiency, robustness, utility, non-redundancy, exhaustively, exploitability, interoperability, job rotation and training level. Flexible organization is a resilient organization that tolerates changes, modifications, adjustments and interchange actors between working posts. Effectiveness deals with the business processes ability to realize the awaited results. Efficiency deals with the business processes capability to make effective results in reduced time and under lower cost and effort. Robustness measures the business processes capability to continuously working in abnormal situations. Utility asks if the organization contains only the necessary organizational elements (non-supplementary processes, activities, actors etc.). Non redundancy asks if the organization contains redundant organizational elements (similar processes, activities, actors etc.). Exhaustively relates to the organization perenniality, (non-missing business processes, activities, actors, etc.). Exploitability measures the rate of using information technology (IT) within the organization. Interoperability refers to the ability of the different processes to cooperate and communicate between them and work in synergy and without ambiguity. Job rotation represents [13] the frequency with which business actors transfer from existing to new positions, under normal circumstances. Higher frequency of employee job rotation in different positions allows the organization to take rapid action when changes are needed. Training [13] measures business actors' agility. Training and cross-training programs provide employees with a wide range of skills that allow them to quickly redeploy when needed. Higher levels of training also equip employees with knowledge and capabilities to effectively perform alternative tasks when they are anticipating and reacting to changes.

The parameters defined for the measurement of information agility are: accuracy, exhaustively, actuality, precision, reliability, flexibility, nonredundancy, non-ambiguity, utility, accessibility, exploitability, publication and security. Accuracy refers to the information correctness and consistency, i.e. no wrongness or contradictions. Exhaustively refers to the information completeness, i.e. non missing statements or elements. Actuality measures the information topicality. Precision refers to the exactitude of the generated results. Reliability measures the capability to restore information in case of loss or destruction. Flexibility deals with the ability to adapt to new conditions resulting from modification, addition or removal of certain informational elements of the system. Non redundancy refers to information similarity, i.e. similar information are redundant. Non ambiguity refers to information clarity, i.e. information must be interpreted as it should be. Utility asks if the organization processes only the necessary data and knowledge, i.e. non supplementary or useless information. Accessibility measures the rate of access to information. Exploitability measures the rate of information computerization. Publication measures the degree of information diffusion inside and outside the organization. Security refers to the information confidentiality, safety and integrity.

Finally, the parameters defined for the measurement of technology agility are: use, usefulness, reuse, utility, reliability, robustness, effectiveness, efficiency, portability, evolutivity, sustainability, adjustability, connectivity, modularity and integration. Technology use measures the frequency of using IT resources. Usefulness measures the ease and facility of using IT resources. Reuse deals with the ability of being reusable later on. Utility refers to the need and necessity for use. Reliability deals with the ability of IT resources to respond correctly to what we ask them to do. Robustness deals with the capability of IT resources to continuously working in abnormal situations. Portability deals with the software resources ability to be easily executable/deployed on different platforms and technologies. Effectiveness deals with the IT resources ability to realize the awaited results. Efficiency deals with the IT resources capability to made effective results in reduced time and under lower cost and effort. Evolutivity deals with the IT resources life aspect. IT with higher evolutivity [13] can better accommodate input changes by increasing or decreasing system load while maintaining a steady state in the face of changing conditions so as to remain viable. Sustainability refers to the ability to endure, or to exist for a long time without significant deterioration. Adjustability deals with the capability of modifying technologies. Technology with higher adjustability allows it to be modified within a shorter time frame, higher frequency, and higher degree of change. Connectivity [13] deals with the degree to which various IT components can exchange data with one another and automatically trigger events to be completed in one of the connected modules. Technology with higher connectivity enables 
seamless collaboration within the organization more easily, allowing the firm higher degrees of freedom with respect to information access and fast, effective response to changes in the environment. Modularity refers to the capability to treat IT components independently. Technology with higher modularity enables the addition and/or removal of technology components without significant costs and time delay. Integration deals with the ability of the technology platform to incorporate new and different technologies that offer a new set of informationprocessing capabilities.

\subsection{Agility Evaluation Method}

The principle of our proposed method for agility evaluation of an e-Government Information System (e-GIS) starts by defining a target degree of agility for this e-GIS, expressed in a target analysis grid. After that, its real degree of agility is evaluated through the real analysis grid. Once the Target Agility Degree (TAD) compared to the Real Agility Degree (RAD), the Agility Gap (AG) is determined and we conclude by the mentions of Acceptable degree of agility (ADA) or Insufficient degree of agility (IDA), in which case it is necessary to bring some corrections and adjustments for the considered e-GIS in sight to refine or redirect the evaluation.

In the following, the product model (section 4.2.1) describes the analysis grids for agility evaluation; whereas the process model (section 4.2.3) prescribes the methodological steps of evaluation.

\subsubsection{Product model}

The product model of the proposed method (Figure 2) is presented by the GAVROCHE model [18] which contains two types of links between the concepts: the link of existency/ dependency and the link of generalization/specialization.

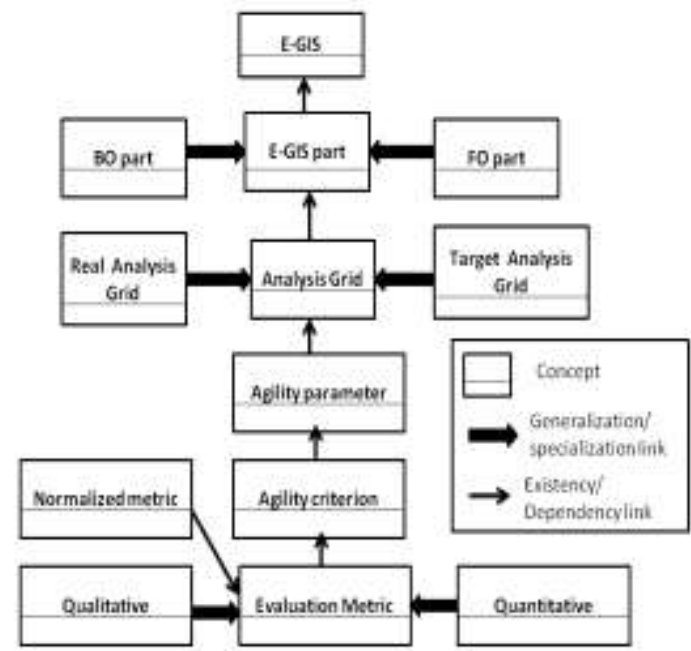

Figure 2. Product Model of the Proposed Method
The existential dependency link allows linking two concepts where the source concept cannot exist without the target concept. As for example the concept E-GIS part cannot exist without the concept $E$-GIS. The specialization/generalization link allows linking a more specialized concept (the source concept) to a more generalized concept (the target concept). As for example, the concepts $F O$ part and $B O$ part specialize the concept E-GIS part.

As shown the product model (Figure. 2), the product of our proposed method is Analysis Grid for agility evaluation. This grid (or conceptual grid) contains agility parameters that characterize FO and BO parts (as seen in section 4.1). Besides, each one of these parameters is in turn obtained by combination of a set of criteria (Table.2)

\section{Table 2. Fragment of the conceptual analysis grid for agility evaluation}

\begin{tabular}{|c|c|c|c|}
\hline \multicolumn{4}{|c|}{ Conceptual Analysis grid } \\
\hline part & parameter & criteria & Metrics \\
\hline \multirow{8}{*}{ FO } & \multirow{3}{*}{ Flexibility } & $\begin{array}{l}\text { Flexibility of the electronic portal to } \\
\text { changes/evolutions of technology } \\
\text { (e.g. Changing platforms, changing } \\
\text { access ways, browsers, etc.) }\end{array}$ & \\
\hline & & $\begin{array}{l}\text { Flexibility of the electronic portal to } \\
\text { changes/ evolutions of end-users } \\
\text { requirements (e.g. personalized } \\
\text { interfaces, customized options etc.) }\end{array}$ & \\
\hline & & $\begin{array}{l}\text { Flexibility of services to changes/ } \\
\text { evolutions in legislation (e.g. } \\
\text { evolution of existing laws, addition } \\
\text { of new laws, etc.) }\end{array}$ & \\
\hline & \multicolumn{2}{|r|}{ Degree of flexibility } & \\
\hline & \multirow{3}{*}{ Reactivity } & $\begin{array}{l}\text { Timeliness (services are performed } \\
\text { with higher response time). }\end{array}$ & \\
\hline & & $\begin{array}{l}\text { Responsiveness (services respond } \\
\text { right from the first time). }\end{array}$ & \\
\hline & & $\begin{array}{l}\text { Interactivity (services are performed } \\
\text { through interactive interfaces). }\end{array}$ & \\
\hline & \multirow{2}{*}{\multicolumn{2}{|c|}{$\begin{array}{l}\text { Degree of reactivity } \\
\text { Degree of FOAgility }\end{array}$}} & \\
\hline & & & \\
\hline \multirow{8}{*}{ BO } & \multirow{3}{*}{$\begin{array}{l}\text { Adaptabili } \\
\text { ty }\end{array}$} & $\begin{array}{l}\text { Adaptability of the internal } \\
\text { organization to changes in structure } \\
\text { hierarchy. }\end{array}$ & \\
\hline & & $\begin{array}{l}\text { Adaptability of the internal } \\
\text { organization to changes in business } \\
\text { processes. }\end{array}$ & \\
\hline & & $\begin{array}{l}\text { Adaptability of business processes } \\
\text { to changes/evolution of technology. }\end{array}$ & \\
\hline & \multicolumn{3}{|c|}{ Degree of adaptability } \\
\hline & \multirow{3}{*}{ Security } & $\begin{array}{l}\text { Security of the physical supports of } \\
\text { information }\end{array}$ & \\
\hline & & $\begin{array}{l}\text { Security of the logical supports of } \\
\text { information }\end{array}$ & \\
\hline & & Security of networks & \\
\hline & \multirow{2}{*}{\multicolumn{2}{|c|}{$\begin{array}{r}\text { Degree of Security } \\
\text { Degree of BO Agility }\end{array}$}} & \\
\hline \multirow{2}{*}{\multicolumn{3}{|c|}{$\begin{array}{r}\text { Degree of BO Agility } \\
\text { Total degree of the e-GIS agility }\end{array}$}} & \\
\hline & & & \\
\hline
\end{tabular}

Agility metrics may be of different natures (quantitative, qualitative); So, in order to unify the interpretation of the results and calculus, agility metrics are normalized on a likert-5 scale, i.e. each criterion is measured using a five point Likert scale, from (1) very low to (5) very high $(0 \leq$ VeryLow $\leq 1$; $1<$ low $\leq 2 ; \quad 2<$ Average $\leq 3 ; \quad 3<$ High $\leq 4 ; \quad 4<$ Very 
high $\leq 5$ ). Due to space limitation, we presented only a fragment of the conceptual analysis grid as an illustrative example. The full conceptual analysis grid is available from the author upon request.

\subsubsection{Assessment models}

Our approach, in order to better apprehend the complexity of the e-GIS, defines four (4) agility assessment models (Table 3) according to the four (4) levels (stages) of the E-GIS development [19]. These levels are explained by the degrees of transformation of the E-GIS front office service, along with the related back office infrastructure. Indeed, for each stage, an appropriate assessment model is associated; and for each assessment model, appropriate formulas are established as follows:

\section{Table3. Agility assessment models}

\begin{tabular}{|c|c|c|}
\hline $\begin{array}{c}\text { E- } \\
\text { government } \\
\text { development } \\
\text { stage }\end{array}$ & Description & $\begin{array}{c}\text { Agility } \\
\text { Assessment } \\
\text { model }\end{array}$ \\
\hline $\begin{array}{c}\text { Stage1: } \\
\text { cataloging }\end{array}$ & $\begin{array}{c}\text { Online presence, } \\
\text { catalogue } \\
\text { presentation, } \\
\text { Downloadable } \\
\text { forms }\end{array}$ & $\begin{array}{c}\text { Simplified } \\
\text { model } \\
\text { (formulas:1,2 } \\
\text { and 3) }\end{array}$ \\
\hline $\begin{array}{c}\text { Stage2: } \\
\text { interaction }\end{array}$ & $\begin{array}{c}\text { Services and } \\
\text { forms online, } \\
\text { working databases } \\
\text { supporting online } \\
\text { transactions. }\end{array}$ & $\begin{array}{c}\text { Extended } \\
\text { model } \\
\text { (formulas: 1, 2, } \\
\text { and 3bis) }\end{array}$ \\
\hline $\begin{array}{c}\text { Stage3: } \\
\text { vertical } \\
\text { integration }\end{array}$ & $\begin{array}{c}\text { Local systems } \\
\text { linked to higher } \\
\text { level systems, } \\
\text { Very similar } \\
\text { functionalities. }\end{array}$ & $\begin{array}{c}\text { Detailed model } \\
\text { (formulas:1, } \\
\text { 2bis and 3bis) }\end{array}$ \\
\hline $\begin{array}{c}\text { Stage4: } \\
\text { horizontal } \\
\text { integration }\end{array}$ & $\begin{array}{c}\text { Systems integrated } \\
\text { across different } \\
\text { functions, One- } \\
\text { stop shopping for } \\
\text { citizens. }\end{array}$ & $\begin{array}{c}\text { More-detailed } \\
\text { model } \\
\text { (formulas:1bis, } \\
\text { 2bis and 3bis) }\end{array}$ \\
\hline
\end{tabular}

Stage 1 (cataloging): in this stage, the complexity of EGIS is very low as the government's strategy focuses only in establishing an online presence via static front office portals. The functionalities are generally limited to online presentation of government information and -in few cases- one-way transactions. According to this least amount of FO functionalities, there is no significant reorganization of the related $\mathrm{BO}$ structure. In fact, a simplified assessment model which assumes that FO and BO parts have the same weight and all the agility parameters and criteria in each part have the same weight too- is associated to this stage. This model evaluates agility using the following formulas $(1,2$ and 3).

Agility of a given parameter ( $\mathrm{Pi}$ ) of a given part (FO/BO) is measured by the following formula (1):

$$
A_{p i}=\left(\sum_{j=1}^{N C} C_{j}\right) / N C
$$

Where:

$$
\begin{aligned}
& \text { - } C_{k} \text { : Metric of the } j^{\text {th }} \text { criterion of Pi }\left(C_{k}\right. \\
& \quad C[0,5]) ; \\
& \text { - NC: number of criteria of Pi. }
\end{aligned}
$$

Agility of a given part (FO/BO) of the E-GIS is measured by the following formula (2):

$$
\begin{aligned}
\mathrm{A}_{\mathrm{FO} / \mathrm{BO}} & =\left(\sum_{\mathrm{k}=1}^{\mathrm{NP}} \mathrm{A}_{\mathrm{Pk}}\right) / \mathrm{NP} \\
\text { Where: } & \\
- & \mathrm{A}_{\mathrm{Pk}}: \text { Agility of the } \mathrm{k}^{\text {th }} \text { parameter of the } \\
& \text { part }(\mathrm{FO} / \mathrm{BO}) . \\
& \mathrm{NP}: \text { number of parameters of the part. }
\end{aligned}
$$

Finally, the overall agility of the E-GIS ( $\left.\mathrm{A}_{\mathrm{E}-\mathrm{GIS}}\right)$ is measured by the following formula (3):

$$
\mathrm{A}_{\mathrm{E}-\mathrm{GIS}}=\mathrm{A}_{\mathrm{FO}}+\mathrm{A}_{\mathrm{BO}} / 2
$$

Where:

$$
\begin{array}{ll}
\text { - } & \mathrm{A}_{\mathrm{FO}} \text { : Agility of the FO part; } \\
\text { - } & \mathrm{A}_{\mathrm{BO}} \text { : Agility of the } \mathrm{BO} \text { part. }
\end{array}
$$

Stage 2 (transaction): this stage is the beginning of the EGIS as a revolutionary entity changing the way people interact with their government. Hence, people are served through FO with two-way transactions; they fill out forms, and government responds by providing confirmations, receipts, etc. Moreover, people move from a passive to active role by not only conducting transactions online, but also participating through online forums that allow them to talk to government officials. Accordingly, the BO issues are much greater in this stage. For example, the changing role played by the government employee. In the precedent stage, many government employees are responsible for processing one way transactions. In this stage, most transactions are automated and the government employees are becoming more an overseer of the process than a simple task-oriented assembly-line worker. To this end, an extended assessment model which takes into account the weights of the FO and BO parts -is associated to this stage. This model evaluates agility using the precedent formulas (1), (2), and the following formula (3bis):

$$
\underset{(3 \mathrm{biS})}{\mathrm{A}_{\mathrm{E}-\mathrm{GIS}}}=\left(\mathrm{A}_{\mathrm{FO}} * \lambda_{\mathrm{FO}}\right)+\left(\mathrm{A}_{\mathrm{BO}} \star \lambda_{\mathrm{BO}}\right) /\left(\lambda_{\mathrm{FO}}+\lambda_{\mathrm{BO}}\right)
$$

Where:

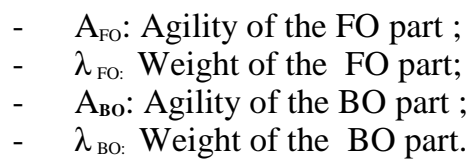


Stage 3 (vertical integration): most second stage systems are localized and fragmented. A natural progression will be the integration of scattered systems at different levels (local, state and federal) of government. If a citizen conducts a transaction with a local agency, the transaction information will be propagated to state and federal counterparts and viceversa. Consequently, at stage 3 , local, state and federal counterparts systems are expected to connect or at least communicate to each other. In fact, parameters such as communication and integration technologies, format of compatibility of electronic data interchange, exposure level of internal legacy system to outside, etc. - become more important in this level of E-GIS complexity. Hence, a detailed assessment model which takes into account the weights of agility parameters is associated to this stage. This model refines the extended model (stage 2) that takes into account the weights of parts, and evaluates agility using the precedent formulas (1), (3bis), and the following formula ( 2 bis):

$\mathrm{A}_{\mathrm{FO} / \mathrm{BO}}=\left(\sum_{\mathrm{k}=1}^{\mathrm{NP}} \mathrm{A}_{\mathrm{Pk}} * \lambda_{\mathrm{Pk}}\right) \underset{\mathrm{k}=1}{/} \sum^{\mathrm{NP}} \lambda_{\mathrm{Pk}} \quad(2 \mathrm{bis})$

Where:

- $\quad \mathrm{A}_{\mathrm{Pk}}$ : Agility of the $\mathrm{k}^{\text {th }}$ parameter of the part (FO/BO).

- $\quad \lambda_{\mathrm{Pk}}$ : is the weight of the parameter $\mathrm{k}$.

- NP: number of parameters of the part.

Stage 4 (horizontal integration): while the vertical integration consists in integrating the E-GIS across different levels of government, the horizontal integration consists in integrating the E-GIS across different functions and services in that a transaction in one agency can lead to automatic checks against data in other functional agencies. In fact, the horizontal integration of government services across different functions of government will be driven by certain criteria (such as efficiency, effectiveness, robustness, reliability, etc.) of vertical integration. Hence, a more detailed assessment model which takes into account the weights criteria- is associated to this stage. This model refines the two precedent models that takes into account respectively the weights of parts and dimensions and evaluates agility using the precedent formula (2bis), (3bis) and the following formula (1 bis):

$A_{P i}=\left(\sum_{j=1}^{N C} A_{C j} * \lambda_{C j}\right)_{j=1}^{N C} / \sum \lambda_{C j}(1$ bis $)$

Where:

- $\quad A_{C j}$ : Agility of the $j^{\text {th }}$ criterion of the $\mathrm{Pi}$.

- $\quad \lambda_{\mathrm{Cj}}$ : is the weight of the criterion $\mathrm{j}$.

- NC: number of criteria of Pi

\subsubsection{Process model}

The process model of our proposed method (Figure 3) is presented by the MAP formalism. The MAP [3] is a labeled directed graph where nodes are intentions whereas the edges are labeled with strategies to achieve these intentions.

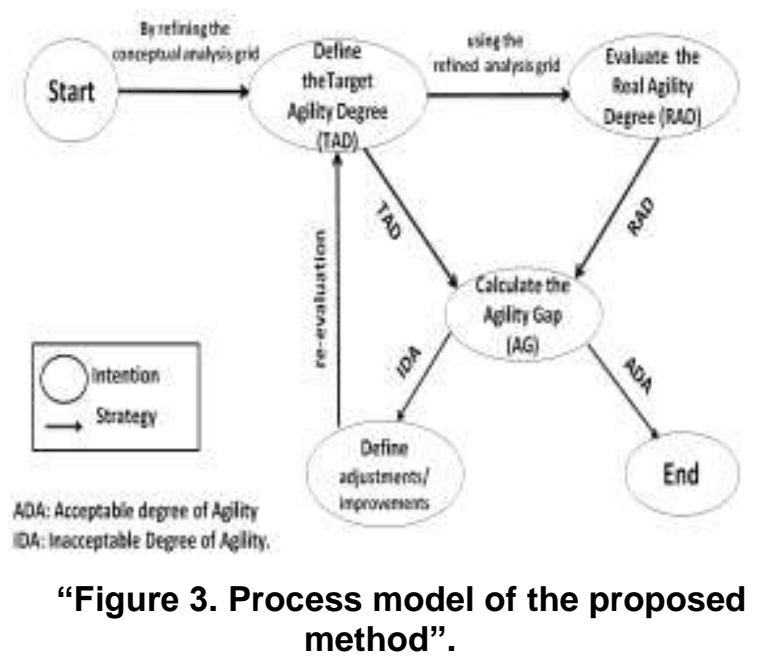

Start and End are standard intentions of MAP that mark respectively the beginning and the end of the process.

Guidelines for defining the target agility degree (TAD): The definition of the target degree of agility is based on refining the conceptual analysis grid -as follows- to obtain the target analysis grid:

- Answering the questions that concern agility criteria so that each response gives the ideal score a parameter should have in the considered part. To this end, data is collected from the in-depth analysis of the E-GIS under study and collaboration with experts to determine ideal metrics from [1 to 5] that each criterion should have in the corresponding parameter.

- Analyzing the collected data and confirm (1) whether each sample of criteria captures its corresponding parameter and (2) whether each sample of parameters captures the construct of agility in their corresponding part (FO, BO). For that purpose, reliability coefficients (coefficient Cronbach's alpha) are calculated with an acceptance level at least 0.7 [20]. Next, in order to achieve higher levels of reliability (closed to 1 ), the Churchill's recommendation [21] is used: "a sample of items can be purified by examining each corrected item to total correlations; and then desecrating items whose elimination improved reliability of the construct until no item's removal increased the construct's overall reliability". Accordingly, parameters are 
refined by refining their corresponding number of criteria; and parts are refined by refining their corresponding number of parameters. Thus a refined analysis grid is obtained.

- Evaluating the agility of parameters using formulas (1) or (1bis). The choice of the appropriate formula depends on the level of complexity of the E-GIS under study (as explained in the previous section).

- Evaluating the agility of parts (FO and BO) using formulas (2) or (2bis). The choice of the appropriate formula depends on the level of complexity of the E-GIS under study (as explained in the previous section).

- Finally, evaluating the overall Target Agility Degree (TAD) of the E-GIS using formulas (3) or (3bis). The choice of the appropriate formula depends on the level of complexity of the E-GIS under study (as explained in the previous section).

Guidelines for evaluating the real agility degree (RAD): the evaluation of the real degree of agility is based on fulfilling the refined analysis grid -as follows- to obtain the real analysis grid:

- Answering the questions that concern agility criteria so that each response gives the real score a criterion has in the considered parameter. To this end, data is collected from the in-depth analysis of the E-GIS under study to determine the metrics from [ 1 to 5] that each criterion has in the considered parameter.

- Second, evaluating the agility of parameters using formulas (1) or (1bis). The choice of the appropriate formula depends on the level of complexity of the E-GIS under study (as explained in the previous section).

- Third, evaluating the agility of FO and BO parts using formulas (2) or (2bis). The choice of the appropriate formula depends on the level of complexity of the E-GIS under study (as explained in the previous section).

- Finally, evaluating the overall Real Agility Degree (RAD) of the E-GIS using formulas (3) or (3bis). The choice of the appropriate formula depends on the level of complexity of the E-GIS under study (as explained in the previous section).

Guidelines for calculating of the agility gap: Once the target agility degree (TAD) is compared to the real agility degree (RAD) we can calculate the agility gap (AG). Agility Gap (AG) is defined as the gap between the TAD and RAD. i.e. $A G=T A D-$ RAD. Once the agility gap (AG) is calculated, we can conclude by the mentions of Acceptable Degree of Agility Gap (ADA) or Insufficient Degree of Agility (IDA), as follows (Figure 4):

$$
\left\{\begin{aligned}
\text { If } A G \in[0,1], \text { then ADA } \\
\text { Else } \\
\text { If } A G \in] 1,5], \text { then IDA }
\end{aligned}\right.
$$

Agility G.AP (AG)

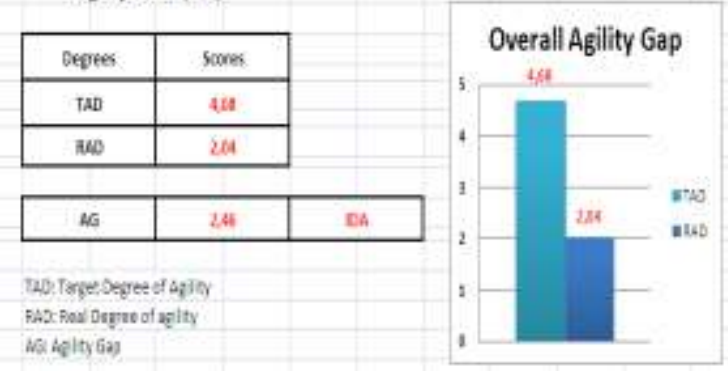

Figure 4. Prototype example of AG evaluation

Practically, the ADA means that the "gap" between the target and the real degrees of agility is low; thus the e-GIS under study is agile; whereas the IDA means the contrary, i.e. the gap between the target and the real degrees of agility is high; thus the e-GIS under study is not agile; in which case some improvements /adjustments are needed.

Guidelines for defining adjustments and improvements: To determine the necessary improvements, a mapping between the target analysis grid and the real analysis grid (Figure 5) is necessary in order to determine non agile parameters on which work must be focused. Once non agile parameters are determined, we can engage the necessary corrections and adjustments. Non agile parameters are determined as follows:

- Calculating the agility gaps (AG) for all pairs of target and real agility degrees of the parameters.

- Concluding by the mentions of:

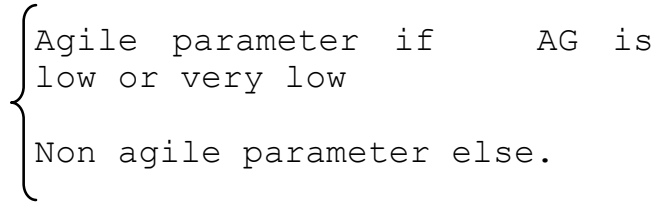




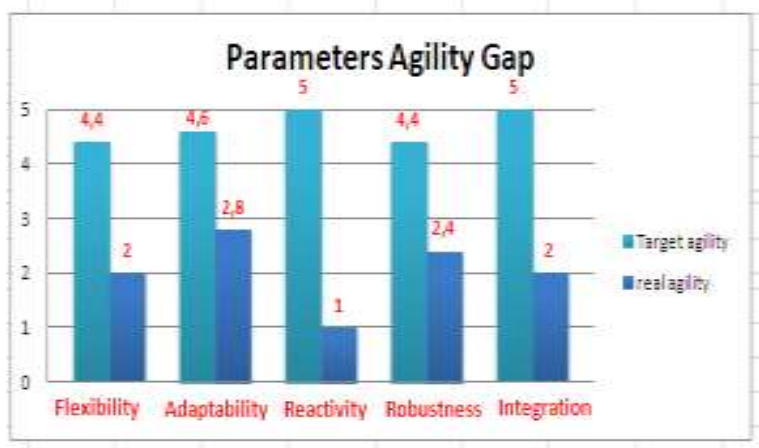

Figure 5. Prototype example of parameters AG evaluation

\section{Conclusion}

In this paper, we presented a state of the art dealing with the concept of agility as well as the main approaches dealing with evaluation of information systems agility. Although all these approaches are important -each one in the domain in which it is applied- their application for evaluation of e-government information systems agility will not work well. This is because e-government information systems differ from the author information systems in the fact that they encompass strategic political and social goals rather than financial ones. In this paper, we presented only the theoretical part of our proposed method for evaluation of e-government information systems agility. An immediate perspective for this work consists in validating it in a practical case study which is actually started in the Algerian ministry of posts and technologies of information and communication within the project of E-ALGERIA 2013

\section{References}

[1] O. Sallard, N. Ali Alyousuf, "Measuring and Evaluating E-Government in Arab Countries", High Level Seminar on Measuring and Evaluating E-Government and 3rd Meeting of Working Group 2 on e-Government and Administrative Simplification., Dubai, 12-13 March 2007.

[2] N. Tsourveloudis, K. Valavanis, D. Gracanin, and M. Matijasevic,"On the Measurement of Agility in Manufacturing Systems", Journal of Intelligent and Robotic Systems, Kluwer Academic Publishers Hingham, MA, USA, 33 (3) . pp. 329 - 342, 2002.

[3] C. Rolland, "L'ingénierie des méthodes : une visite guidée". e-TI - la revue électronique des technologies d'information, Premier Numéro, 25 octobre 2005.

[4] T.W. Olle, J. Hagelstein, I.G. MacDonald, C. Rolland, H.G. Sol, F.G.M. Van Assche, and A.A.VerrijnStuart,'Information Systems Methodology: a Framework for Understanding". Addison-Wesley, 1992.
[5] S.L. Goldman, K. Preiss, "21st Century Manufacturing Enterprise Strategy", Bethlehem, PA: Iacocca Institute, Lehigh University, 1991.

[6] T.P. Kidd,“Agile Manufacturing: Forging New Frontiers”. London, Addison-Wesley, 1994.

[7] K. Conboy, B. Fitzgerald B, 'Towards a Conceptual Framework of Agile Methods: A Study of Agility in Different Disciplines", In proceedings of the 2004 ACM Workshop on Interdisciplinary Software Engineering Research (WISER), Newport Beach, CA, USA, November. ACM Press NY. 2004, PP 37-44.

[8] H.T. Goranson, "The Agile Virtual Enterprise: Cases, Metrics, Tools", Quorum Books editions, 1999. ISBN 1 567-20264-0.

[9] R.J. Houghton, O.A. El Sawy, P.Gray, C. Donegan, A. Joshi, "Vigilant Information Systems: The Western Digital Experience", In Desouza K. C. editor, "Agile Information Systems: Conceptualization, Construction, and Management", Elsevier, Burlington, USA, 2007, ISBN 10: 0-7506-8235-3, pp. 222-238.

[10] K.C. Desouza, "Preface", In Desouza K. C. editor, Agile Information Systems: Conceptualization, Construction, and Management, Elsevier, Burlington, USA, 2007, ISBN 10: 0-7506-8235-3

[11] E. Stamos, E. Galanou, "How to evaluate the agility of your organization: Practical guidelines for SMEs" VERITAS, 2006.

[12] R. Imache, S. Izza, and M. Ahmed-Nacer, "An Enterprise Information System Agility Assessment Model". Computer science and information systems (CSIS), 2012, Vol. 9, $\mathrm{N}^{\circ}$ 1, pp, 107-133.

[13]T.W. Lui, G. Picolli, "Degree of agility : Implications from Information Systems Disign and Firm Strategy ", In Desouza K.C editor, Agile information Systems, Conceptualization, Constuction and Management, Elsevier, berligton, USA, 2007, ISBN 10:0-7506-8235-3, pp.122-133.

[14] M. Grimsley, A. Meehan, "E-Government information systems: Evaluation-led design for public value and client trust", European Journal of Information Systems (16), pp134-148, 2007.

[15] F. Bannister, "Dismantling the Silos: Extracting New Value from IT Investments in Public Administration", Information Systems Journal, 2001(1), pp, 65-84.

[16] B. Farbey, F. Land, and D. Targett, "A Taxonomy of information systems applications: the benefits evaluation Ladder", European Journal of Information Systems, Vol 4, 1995, pp, 41-50.

[17] M. Vintar, M. Kunstelj, M. Decman, A. Leben and B. Bercic, "The development of measurement system of IT usage in the public sector in Slovenia", Internal project report, School of Public Administration, Ljubljana, 2002. 
[18] A. Khadraoui, L. Michel, S. Daphné, S.Turki, "Ingénierie des systèmes d'information pour l'egouvernement". E-TI, la revue électronique des technologies de l'information, Premier numéro, 2005.

[19] K. Layne, J. Lee, "developing fully functional egovernment: a four stages model". Government Information Quarterly, 18, 2004, pp. 122-136.

[20] L.J. Cronbach,"Coefficient alpha and the internal structure of tests”. Psychometrika, 16, 1951, pp, 297-333.

[21] G.A. Churchill, "A paradigm for developing better measures of marketing Constructs", Journal of Marketing Research, 1979, XVI, pp, 64-73. 